\title{
Food waste knowledge, attitudes, and behavioral intentions among university students
}

\author{
Manar A. Alattar, ${ }^{\text {* }}$ James DeLaney, ${ }^{\mathrm{b}}$ Jennifer L. Morse, ${ }^{\mathrm{c}}$ and Max Nielsen-Pincus ${ }^{\mathrm{d}}$ \\ Portland State University
}

Submitted May 3, 2019 / Revised August 19, September 14, and October 5, 2019 / Accepted October 8, 2019 /

Published online March 18, 2020

Citation: Alattar, M. A., DeLaney, J., Morse, J. L., \& Nielsen-Pincus, M. (2020). Food waste knowledge, attitudes, and behavioral intentions among university students. Journal of Agriculture, Food Systems, and Community Development, 9(3), 109-124. https://doi.org/10.5304/jafscd.2020.093.004

Copyright (C 2020 by the Authors. Published by the Lyson Center for Civic Agriculture and Food Systems. Open access under CC-BY license.

\begin{abstract}
After policy change, educational programming has been cited as one of the most powerful tools for improving food systems and decreasing food waste. University students represent a population in which emerging habits, skills, and identity may

a* Corresponding author: Manar A. Alattar, Department of Environmental Science \& Management, Portland State University; P.O. Box 751; Portland, OR 97207 USA; manaraalattar@gmail.com

Alattar's present addresses are Department of Biology, Portland Community College; 12000 SW 49th Ave.; Portland, OR 97219 USA; and Environmental Studies Department, University of Portland; 5000 N. Willamette Blvd.; Portland, OR 97203 USA.

b James DeLaney, Department of Psychology, Portland State University; 1825 SW Broadway; Portland, OR 97201 USA.

c Jennifer L. Morse, Department of Environmental Science \& Management, Portland State University; P.O. Box 751; Portland, OR 97207 USA.

d Max Nielsen-Pincus, Department of Environmental Science \& Management, Portland State University; P.O. Box 751; Portland, OR 97207 USA.
\end{abstract}

be targeted easily and changed through on-campus educational programming. To understand how to best implement programming on impacts of food, food waste, and related issues, the factors that underlie students' behaviors related to food waste must be understood. We analyzed factors that influence food waste-related behaviors within a university student population to understand the potential for improving targeted, school-based food waste diversion programming. Four hundred and ninety-five students were surveyed to: (1) identify self-reported knowledge, attitudes, and behaviors

\section{Funding Disclosure}

This work was supported through funding from the Campus Sustainability Office at Portland State University and the Edward D. and Olive C. Bushby fund at PSU. This work was also supported by the National Science Foundation Integrative Graduate Education and Research Traineeship (grant no. 0966376: "Sustaining ecosystem services to support rapidly urbanizing regions"). Any opinions, findings, and conclusions or recommendations expressed in this material are those of the authors and do not necessarily reflect the views of the National Science Foundation 
related to food waste; (2) explore underlying factors driving food waste-related behaviors through exploratory factor analysis (EFA); and (3) understand the interactions between factors within a regression framework. Participants reported that they most often left food on their plate because it did not taste good or they had overestimated portion size. A majority of participants already performed many food waste reduction behaviors, and were both interested in taking action and aware that their efforts could make a difference. Food management skills, compost attitudes, sustainability attitudes, and reported household food waste were correlated, in various ways, with both intent to reduce and reported food waste reduction behaviors. Opportunities for improving university-related food waste programming through this data are explored.

\section{Keywords}

Food Waste, Sustainability, Behavior Change, Environmental Education, Behavioral Factors, Exploratory Factor Analysis

\section{Introduction}

Human need (biophysical) and want (preferences and habits) for food are arguably the primary way in which we shape our world. Food is also central to culture and community. The global food cycledefined as the system encompassing all activities, interconnections, drivers, and outcomes related to the production, distribution, consumption, and waste of food worldwide (Neff, 2015)—drives environmental, social, and political change across time, culture, and geographic region. Agriculture and other land uses related to food production have one and a half times the greenhouse gas (GHG) footprint of the global transportation sector (Bajželj, Allwood, \& Cullen, 2013; Olhoff, 2018). Additionally, agriculture is a leading cause of biodiversity loss and pollution (Feldstein, 2017) and contributes significantly to racial, gender, labor, and other social inequities (Patel, 2012; Penniman, 2018).

Not only does the food cycle have significant global impact, but it also remains highly inefficient. Up to $40 \%$ of the total edible food in the U.S. and $30 \%$ worldwide is wasted (Food and Agriculture
Organization of the United Nations [FAO], 2013). Loss of edible food occurs at each stage within the food cycle from production to consumption, but eaters (consumers of food) are responsible for the bulk $(60 \%)$ of food waste along the food cycle in countries with more affluent economies (Lipinski et al., 2013). Factors that influence food wasterelated behaviors are diverse and context-specific (Thomas \& Sharp, 2013). Therefore, mobilizing change will rely on policy intervention, skill building, community mobilization, and grassroots education, among other things (Graham-Rowe, Jessop, \& Sparks, 2014; ReFED, 2016).

As participation in higher education increases, marriage and childbearing are delayed, and technology transforms the way we interact, college age is emerging as a separate and essential period of life in which significant changes occur and defining lifestyle skills and habits emerge. Research indicates that college-aged adults tend to have an increased risk of becoming obese, decreased physical activity, increased leisure-time computer use, and decreased overall quality of diet and vegetable consumption (Nelson, Story, Larson, Neumark-Sztainer, \& Lytle, 2008). Additionally, marketers of sugary beverages and snacks heavily target adolescent and collegeaged (and even younger) populations as important customers and to develop brand loyalty (Nestle, Bittman, \& Baer, 2015). Young adulthood is also an important time for developing identity, self-efficacy, and life skills (Nelson et al., 2008). Therefore, this period is an essential and optimal time for behavioral interventions related to food intake and health. Furthermore, the university setting provides a microcosm that is excellent for developing and implementing specified and targeted behavioral interventions. Research shows that students targeted by food- and health-related programming on-campus, particularly with the support of mentors, demonstrate an increased intent to change healthrelated behavior after programming (McComb, Jones, Smith, Collins, \& Pope, 2016). Therefore, more research on food-related interventions targeted to early adults and on college campuses may have the potential to affect both individual behavior and develop a more skilled community in relation to health and sustainable food.

Furthermore, community education, generally, 
has been found to be a primary tool for addressing food waste. Rethink Food Waste through Economics and Data (ReFED) gathered available data and expert input, and performed an assessment of cost effectiveness and potential impacts of 27 solutions that could be used to address food waste in the U.S. (ReFED, 2016). Community education was ranked as the second most economically feasible solution to food waste (second only to standardizing food labeling) (ReFED, 2016). Educational programming was also reported as the solution with the second largest potential for GHG reductions, after centralized composting (ReFED, 2016). While the ReFED report was meant to inform policy, it did not assess policy change as a specific potential solution. Policy change, however, remains one of the most effective methods for addressing food waste, as is demonstrated in examples such as grocer donation requirement laws in Europe, implementation of fee-by-food weight systems in Asia, and implementation of composting infrastructure in many cities worldwide (Chrisafis, 2016; Chrobog, 2015; Evans, 2011). Additionally, educational programs in the U.K. and elsewhere have shown considerable success in addressing food waste behaviors, as well (Quested, Ingle, \& Parry, 2013). For example, the Love Food Hate Waste campaign funded through the Waste and Resources Action Programme (WRAP) in the U.K. is unique in that both significant funding and research efforts are combined to engage eaters in food-waste diversion skills. A 1.1 million ton (13\%) reduction in annual household food waste in the U.K. between 2007 and 2010 is partially attributed to this programming (Quested, Marsh, Stunell, \& Parry, 2013).

So, why do eaters waste food? Food waste behaviors are influenced by many, often competing, factors (Benítez, Lozano-Olvera, Morelos, \& Vega, 2008; Evans, 2012; Graham-Rowe et al., 2014). Cost and convenience, including accessible infrastructure like city composting, are strong determinants of food waste diversion behaviors (Pelletier, Dion, Tuson, \& Green-Demers, 1999; Refsgaard \& Magnussen, 2009). The role of cost and convenience, in general, to behavior determination is well established in many behavioral and motivational theories, including expectancy-value theory and the energization theory of motivation (Eccles \& Wigfield, 2002; Fiske, Gilbert, \& Lindzey, 2010). Even minor environmental cues and conveniences such as smaller plate size, absence of cafeteria trays, displaying healthier options before less healthful ones, and precutting fruits instead of serving them whole, can encourage food waste diversion and healthier eating habits (Freedman \& Brochado, 2010; Lehner, Mont, \& Heiskanen, 2015; Moseley \& Stoker, 2013).

Knowledge and skills specific to food management are also essential to food waste diversion (Graham-Rowe et al., 2014; Whitehair, Shanklin, \& Brannon, 2013). Food management skills have been the focus of various food waste diversion campaigns and interventions (Oliver, 2010; Pollan, 2008; Quested et al., 2013). Presumably, having specific food-related knowledge and food management skills decreases the actual and perceived costs of food preparation and waste management. In fact, consumer perception of their ability to affect systems is also important in determining action (Eccles \& Wigfield, 2002).

Both general sustainability beliefs and beliefs specific to food waste have been shown to influence plate waste (Whitehair et al., 2013). Emotions such as guilt are also important to food waste diversion (Graham-Rowe et al., 2014; Leigh Gibson, 2006). Nevertheless, even after acknowledging many factors important for food wasterelated behavior change, ingrained consumption habits are difficult to change (Graham-Rowe et al., 2014).

Food use labeling is also a major driver of food waste, causing up to $20 \%$ of household waste (Leib, Ferro, et al., 2013; Neff, Spiker, \& Truant, 2015; WRAP UK, 2017). The vagueness of food use labels and the lack of regulated standards lead to a considerable amount of consumer confusion about how date labels translate to food safety, thus resulting in significant food waste globally (Leib, Ferro, et al., 2013; WRAP UK, 2017).

Understanding the impacts of these factors on food-waste behaviors and determining how to influence them through targeted interventions are necessary to promote food waste diversion efforts. In this study, we analyzed factors that influence food waste-related behaviors within university stu- 
dent populations to understand the potential for improving targeted, school-based food-waste diversion programming. Food waste diversion is defined here as all manners of diverting edible food from the landfill, including more efficient procurement and management of food.

We developed a simplified diagram (Figure 1) of the main factors on which we built our survey instrument. Although these are the factors on which our analysis relied, as discussed previously, food waste-related behaviors are complex. We also acknowledge that positive self-reports related to behavioral and affective factors do not directly lead to action. Therefore, we included both "action" and "intention to act" as separate outcomes in our analysis. They are represented in our simplified diagram as two factors loosely, but not directly, associated with one another (Figure 1).

We analyzed 495 surveys on food waste administered to university students using a three-step approach. First, we assessed average reported food waste attitudes, knowledge, intent, and behaviors compared to those reported nationally (Objective 1). Second, we determined the underlying factors that influence reported food waste diversion behaviors through an exploratory factor analysis (EFA) (Objective 2). Third, we considered relationships between emergent factors within a regression framework (Objective 3).

\section{Method}

\section{Setting and Participants}

Our study took place during the 2015 academic year at Portland State University (PSU), located in downtown Portland, Oregon, U.S. With an enrollment of 28,000 students, PSU is the largest university in Oregon. Demographically, $56.6 \%$ identify as White, $8.4 \%$ as Asian, $12.5 \%$ as Latino, $7.0 \%$ as international, $3.3 \%$ as African American, $1.1 \%$ as Native American, $6.0 \%$ as multi-ethnic, $0.06 \%$ as Native Hawaiian/Pacific Islander, and $4.6 \%$ as other (PSU University Communications, 2016). Full-time students represent $61 \%$, and part-time represent $39 \%$. A majority of students commute (approximately $80 \%$ ), while $10 \%$ reside in university housing on campus (Housing and Residence Life, 2019; University Communications, 2017).

Two cafeterias serve students, along with various options throughout the urban area. Most of our surveying was conducted in the residence-hall cafeteria as part of a campuswide effort spearheaded by the Campus Sustainability Office (CSO) to begin to understand food waste behaviors. A full-scale composting program in residence halls was rolled out in 2013 (Siegrist, 2015), a couple years before our survey. Therefore, all residents have access to composting options in their dormitories. Furthermore, there are some compost re-

\section{Figure 1. A Simplified Conceptual Figure of Various Underlying Factors that Influence Food Waste Diversion Behaviors}

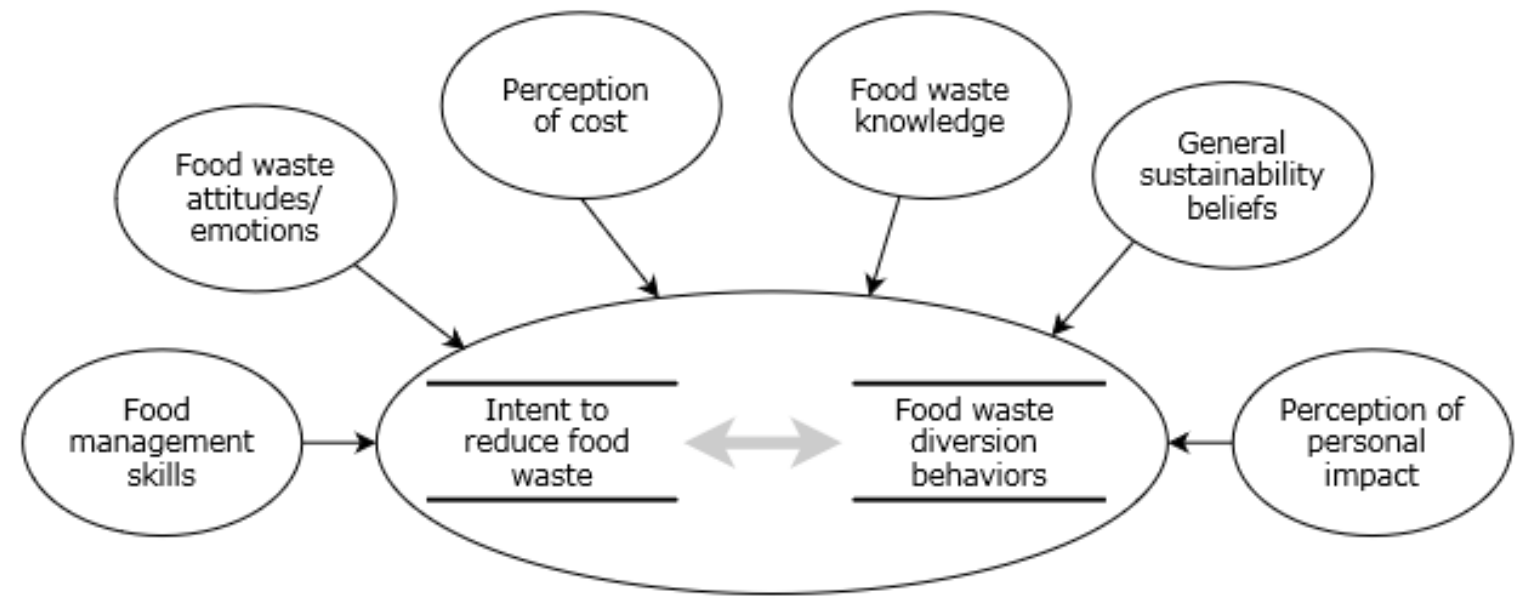


ceptacles throughout campus, although not in all mid-point receptacles (the divided containers that have subsections for landfill-bound trash, recyclable glass, and sometimes other materials). The residence hall cafeteria programming emphasizes local, sustainable food options year-round; for example, it composts all food scraps, highlights local sourcing, and encourages students to participate in Meatless Mondays. The cafeteria hosts an average of 175 people at breakfast, 400 people at lunch, and 500 to 600 people at dinner each day (C. Wapelhorst, personal communication, 2015).

Although the residence hall cafeteria avoids food waste specifically by composting all food waste that comes in through the tray returns (the only waste receptacle in the cafeteria), on the campus overall an average of $25 \%$ of landfill-bound waste is food scraps (and food scraps make up $36 \%$ of the landfill-bound compostable material in general) (Doherty, Brannon, \& Crum, 2013). This includes more than 500 tons per year of valuable food scraps that could be diverted (Hair, 2013). As an institution, the university is working toward a $25 \%$ reduction in waste generation and $10 \%$ reduction in its landfill-bound waste by 2030 as part of its Climate Action Plan (CSO, 2010).

A total of 495 surveys were collected through convenience sampling in the school cafeteria, three freshman classes, and online throughout campus. At the cafeteria, students were approached while in line to pay for food or while eating, and returned their completed questionnaires after their meal. Students in some freshman courses were given questionnaires during a Campus Sustainability Office class presentation. The online survey was set up in Qualtrics (Qualtrics, Provo, Utah) and distributed by email to students in various departments throughout the university.

\section{Data Collection}

The survey instrument was designed to measure food-waste related attitudes, knowledge, intent, reported behaviors, and general sustainability beliefs (Graham-Rowe et al., 2014; Lipinski et al., 2013; Neff et al., 2015; Refsgaard \& Magnussen, 2009). Questions (Table 1) were modeled from previous literature on food waste, but developed further based on knowledge of the specific population, as described below. Cognitive interviews were conducted and survey experts were consulted to establish the content validity of the instrument.

Respondents were asked 24 questions with Likert scales and three questions with written answers (Table 1). All Likert-type questions were given a five-point response scale that ranged from "Strongly agree" to "Strongly disagree," with "Neutral" as the middle anchor point. A 5-point scale allows for sufficient variation within the scale without risking participant reluctance to choose extreme answers on a wider scale (Boslaugh, 2013). Questions written in anti-food waste diversion form (for example, "I do not like composting") were reverse coded for analysis. Basic university-related demographic questions were also included.

Food waste knowledge and knowledge of oncampus resources were measured through questions that have been used in other food-waste studies (Leib, Ferro, et al., 2013; Quested et al., 2013) and questions on specific PSU campus-related food waste diversion knowledge (Pelletier et al., 1999; Whitehair et al., 2013). For example, questions included "I understand food freshness labels" and "I know about the campus composting program." Respondents' knowledge was also probed by asking them to estimate the percent of food waste at various consumer levels: an average American household, the campus community, and the U.S. as a whole. Additionally, respondents were asked to pinpoint waste in the food cycle from production to consumption. Food waste estimate responses were compared to percent averages for "North American and Oceania" reported by Lipinski et al. (2013) to determine how accurately students perceived consumer waste generation compared to preconsumer waste generation. Household and national estimates were compared to those reported in Gunders (2012) and Parfitt, Barthel, and Macnaughton (2010) to determine if students generally over- or underestimated their personal food waste compared to other average Americans. Previous research has indicated that Americans underestimate their own household food waste by up to $47 \%$ (McDermott, Elliott, Moreno, Broderson, \& Mulder, 2019).

Intent and interest in food waste reduction were measured with questions such as "I put effort 
into reducing food waste" and "I am interested in taking action to prevent food waste" (Eilam \& Trop, 2012; Hebrok \& Boks, 2017; Neff et al., 2015). Food management skills have been cited as important in food waste generation (Graham-Rowe et al., 2014; Neff et al., 2015; Vidgen \& Gallegos, 2014) and were measured using a series of questions: "I eat leftovers," "I check the refrigerator before shopping," and "I compost my food scraps." Students were also asked to estimate their own household waste and the percentage of food that is wasted from that which they purchase overall.

Attitudes towards food waste were measured with both cognitive and affective statements. Cognitive statements included items such as "Food waste does not bother me" and "My individual actions towards food waste do not make a difference" that are similar to questions posed in other studies (Brook Lyndhurst, 2007; McKenzie-Mohr et al., 1995; Neff et al., 2015). The affective component was measured with the additional items: "I dislike composting," "When I compost I feel like I'm contributing to the greater good," and "Composting stinks and is gross." "I don't think the food I throw away costs much money" measured the perceived cost of food waste. These items were generated by the authors.

Broader sustainability beliefs were probed indirectly with the following questions: "I believe that many materials can be reused or recycled into something new," "I believe proper waste disposal makes a positive environmental impact," "I would like to see more programs that help reduce food waste," and "I would enroll in a course with a sustainability theme." Participants were also directly asked about the amount of food they wasted, as a percentage of total food, and the reasons for that food waste with the question, "I generally leave food on my plate because?" with multiple potential answers. Basic, university-related demographic questions were also asked, including age, gender, academic level, and whether students lived on-campus.

General Frequency Analysis (Not Applicable to $E F A)$

General frequency analysis of the data allowed for initial insight into behavioral and dispositional re- sponses and a comparison to previously published data, where appropriate (Objective 1). Specifically, for summary statistics (but not for the EFA), when participants "agreed" with a statement, the results presented are a sum of "agree" and "strongly agree" responses. Similarly, if participants "disagreed," the "disagree" and "strongly disagree" responses were combined.

\section{Factor Analysis}

We conducted an exploratory factor analysis (EFA) to explore the underlying factor structure of the 24 Likert items (Objective 2) and generate response variables for the regression analysis. As opposed to a hypothesis-driven endeavor, an exploratory method explores which factors were present but maintains methodological flexibility to better understand and utilize potential unexpected correlations among items (Bartholomew, Steele, Galbraith, \& Moustaki, 2008).

Following the data screening, the EFA was conducted using a multistep process and clear set of decision rules (Williams, Onsman, \& Brown, 2010). First, a principal axis extraction method was used because it is robust against non-normally distributed variables (Fabrigar, Wegener, MacCallum, \& Strahan, 1999). The analysis was performed on a polychoric correlation matrix, which is a modified version of Pearson's correlation that is more appropriate for ordinal data, using oblique rotation to allow for some correlation between factors (Browne, 2001; Lorenzo-Seva \& Ferrando, 2015). Second, we examined the item-loadings and cross-loadings and retained only those with eigenvalues greater than one (Costello \& Osborne, 2005). Finally, we retained factors if: (a) they contained at least three items with loadings greater than 0.32 , and (b) no cross-loadings of 0.32 or above (Yong \& Pearce, 2013). Multi-item indexes were generated for each factor by averaging the responses to questions within each factor. All indexes were evaluated for internal correlation using Cronbach's alpha (Boslaugh, 2013). Pairwise deletion, which leaves all available cases without removing all data from a given respondent (Schafer \& Graham, 2002), was used for all steps in the analysis. This deletion method allows for the analysis of all available data, 
avoiding the additional data loss that occurs when list-wise deletion is utilized.

\section{Regression Analysis}

The relationship of the measured factors and reported individual food waste to both "intent" and "food waste diversion behaviors" (Figure 1) were explored using linear regression (Objective 3). The factor indexes for these two concepts were used as the dependent variable in separate models. This was done to get a more complete understanding of the impact of factors on one another within the model (Figure 1). Models were reduced to include significant factor indexes.

Although there are obvious limitations to using indexes based on self-reported behavior, it is appropriate due to the dispositional and behavioral data being collected and is common to this type of research (Barr, 2007). Predictor variables were tested for multicollinearity within the regression model using a variance inflation factor (VIF); no multicollinearity was detected below three. Data analysis was done in SPS) for Windows, version 24.0 (IBM, Armonk, NY) and R version 3.2.4 (R Core Team, Vienna, Austria).

\section{Results and Discussion}

\section{Sample Characteristics and Demographics}

A total of 495 surveys were collected, 332 from the residence hall cafeteria, 99 in freshman inquiry (required freshmen core) classes during class visits from the Campus Sustainability Office, and 64 online. The average age of respondents was 21, with a range of 18 to 58 years. Of participants, $54 \%$ were female and $42 \%$ male. A majority ( $n=490,94 \%$ of respondents) were undergraduate students, and three $(<1 \%)$ were postbachelor students. A majority $(n=377,76 \%)$ lived in residence halls on campus. On average, participants ate at the residence hall cafeteria eight times a week and at the general school cafeteria once a week. On average, the house or dorm room of participants had two members.

\section{General Frequency Analysis}

Participants reported wasting an average of $18 \%$ of the food they bought, but perceived that average
Americans were more wasteful (35\% on average) (Figure 2). They estimated that $50 \%$ of food produced nationally was wasted (Figure 2 ). Thirty percent $(n=150)$ of students reported that national food waste was in the $30-40 \%$ range.

This range is significant, because other studies show that an average of $30-40 \%$ of food produced in the U.S. is wasted (Figure 2; Buzby, Wells, \& Aulakh, 2014; Gunders, 2012). In regard to household waste, research shows that Americans do indeed waste between $15 \%$ and $30 \%$ of the food they buy (Parfitt et al., 2010; Thyberg \& Tonjes, 2015). Additionally, most Americans underestimate their own contribution to food waste compared to others (Quested et al., 2013). Although participants in our study reported an average household waste within this range, they also perceived themselves as less wasteful than others.

In addition to estimating their personal household waste, students estimated the amount of food waste along the food cycle that consumers were directly responsible for, that is, waste occurring after purchase of food. Students reported an average of $35 \%$ food waste by consumers along the food cycle, and $65 \%$ percent waste occurring upstream of the consumer (Figure 2).

The participants' perception of consumer waste is a significant underestimate; research shows that about $60 \%$ of food waste, in countries with higher income, occurs in the consumption phase (Figure 2; Lipinski et al., 2013). The participants' underestimate is consistent with previous research in which participants tend to downplay the contribution of consumers to food waste and exaggerate the percentage of waste that occurs upstream of the consumer (Neff et al., 2015; Thomas \& Sharp, 2013). On the other hand, students perceived the U.S. as more wasteful of food than it is, estimating $50 \%$ food waste, whereas research indicates a true value between 30\% and 40\% (Gunders, 2012).

When asked for the single most common reason they left food on their plate, $55 \%$ of participants said because it "doesn't taste good," $31 \%$ because they "overestimated the portion size," $9 \%$ because they "don't have time to eat it," $6 \%$ because they are "being aware of their caloric intake," and 3\% did not know or declined to answer. Four percent of respondents chose "Other" and dictated 


\section{Figure 2. Average Perception of How Much Food Is Wasted Along the Food Cycle in the U.S. and at Vari- ous Consumer Levels}

Black diamonds $(\diamond)$ represent the estimated "true" values of food waste for each level as reported in the literature (Doherty et al., 2013; Gunders, 2012a; Lipinski et al., 2013; Parfitt et al., 2010). Percent average household can be compared to the food waste of an average American, to its right, but no true value is given as the true value differs for each individual. Standard deviation of responses are represented with error bars.

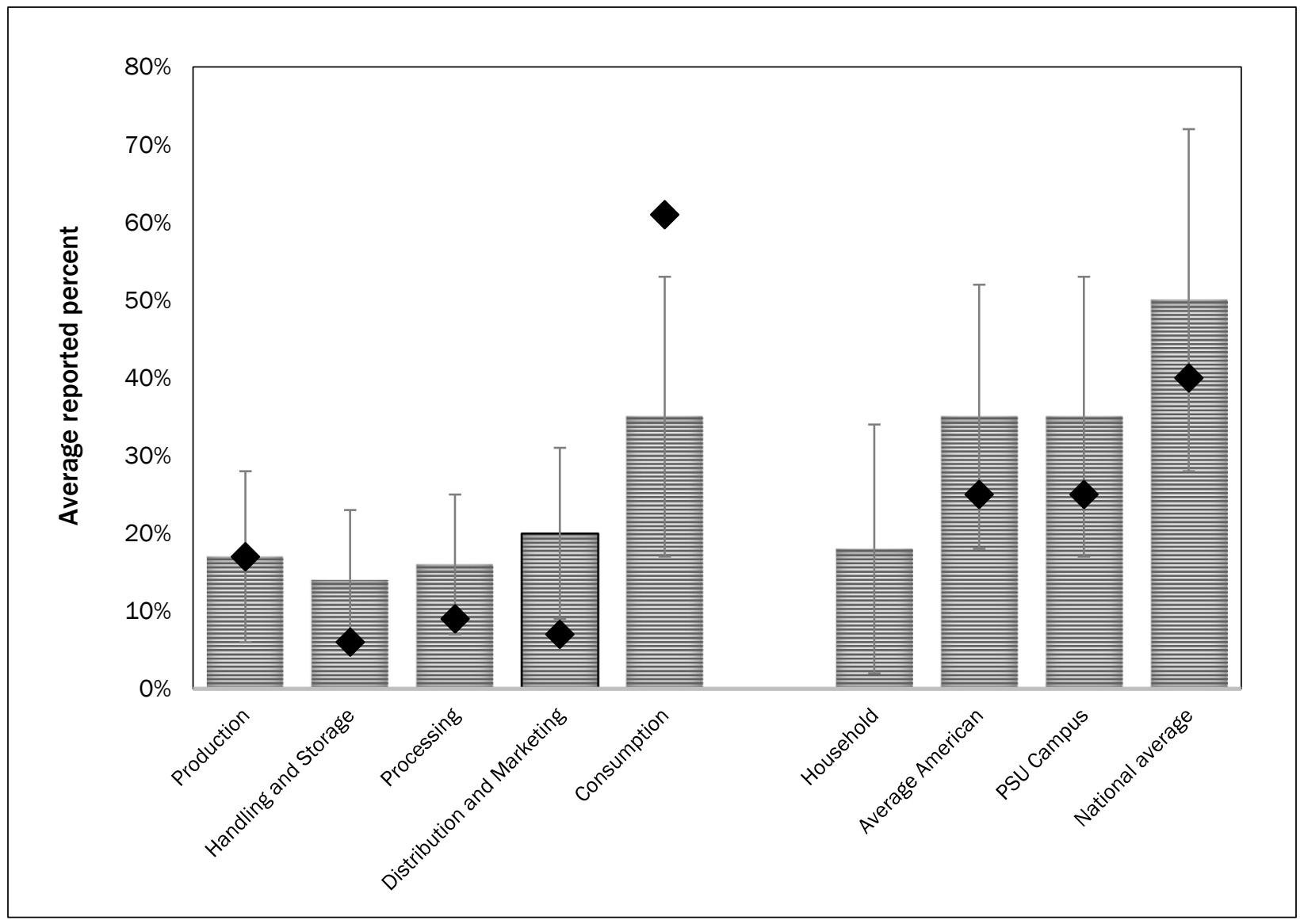

their top reason for wasting food; these included (each less than $1 \%$ of total respondents) that they were sick or felt sick, did not or usually did not leave food waste, were not hungry, realized that dietary restrictions were not met, various responses related to portion size, and various responses related to the quality of the food. One respondent noted an eating disorder and another said "I don't care."

In comparison, European food studies of meals eaten outside the home cited portion size or ordering too much as the main reason for plate waste. Being full, dislike of the taste, smell, or preparation of the food, and social influence were also cited as reasons for plate waste (Betz, Buchli,
Göbel, \& Müller, 2015). Plate waste was also perceived by the respondents in these studies as not the customer's responsibility or out of their control (Oliveira, Pinto de Moura, \& Cunha, 2016).

In regards to food waste diversion thoughts and behaviors in our study, $71 \%$ of participants agreed that they thought about the food waste they generated; $70 \%$ put effort into reducing food waste; $65 \%$ were interested in taking action; and only $23 \%$ talked to others about food waste. Thirty-six percent composted their own food scraps. Eighty-two percent ate leftovers; 77\% checked the refrigerator before shopping; and 62\% made shopping lists. It should be noted that only $38 \%$ prepared or cooked some of their own meals. 
With respect to attitudes, only 5\% reported that "food waste doesn't bother them"; 4\% "dislike compost and composting"; 7\% of participants agreed that if the compost, they "don't need to worry about source reduction (buying/preparing less food to avoid waste)"; and 4\% agreed that food waste does not bother them because it breaks down in the landfill. Forty-four percent of participants felt like composting "contributed to the greater good." Only 10\% agreed that "composting stinks and is gross" and only 11\% agreed that their "actions towards food waste do not make much of a difference."

This data was relatively consistent with previously published research, in which only $9 \%$ of participants said that food waste did not bother them at all, approximately $75 \%$ of respondents used leftovers in future meals (sometimes or often), approximately $90 \%$ checked their refrigerator and cupboards before shopping (sometimes or always), and approximately $85 \%$ made shopping lists (sometimes or always) (Neff et al., 2015).

In terms of general sustainability beliefs, $84 \%$ agreed that "materials can be reused or recycled into something new," 89\% agreed that "proper waste disposal makes a positive environmental impact," and 64\% agreed that they "would like to see more programs on campus that help reduce food waste." Comparable research at another university campus also indicated high levels of agreement with sustainability-related items, even before waste reduction programming (Whitehair et al., 2013).

\section{Factor Analysis and Regression Models}

The EFA resulted in five factors based on our selection criteria. The items factored into categories (Table 1) similar to those that we attempted to measure (Figure 1), including clear factors for "Intent to decrease food waste" and "Food waste diversion behaviors." Factors represented about 55\% of the variance in survey responses. The questions in each factor were averaged to produce factor indexes for the regression model. The factor indexes for intent and food waste-related behaviors were used as dependent variables to determine how the other factors and reported household food waste interacted with these constructs.

The food waste diversion behavior model $(n=495)$ indicated that three variables were most significantly $(p<0.01)$ related to the food wasterelated behavior index factor variable (after model reduction): intent to decrease food waste $(p<0.01)$, composting $(p<0.001)$, and waste attitudes $(p<0.001)$ (Table 2, column 1). The model was highly significant as assessed by an analysis of variance $(A N O V A)\left(p<0.001, \mathrm{R}^{2}=0.242\right)$. Interestingly, the composting index was negatively correlated with food waste diversion intent, but attitudes toward composting were still positively correlated. This may indicate that those who divert food waste have to worry less about composting. It is also consistent with research showing that those who compost report worrying less about source reduction (Brook Lyndhurst, 2007; Neff et al., 2015; Refsgaard \& Magnussen, 2009). Due to the complexity of factors that influence human psychology and behavior, models explaining 20\% to $30 \%$ of variance are considered beneficial and useful (Bartholomew et al., 2008).

The model for intent to decrease food waste $(n=495)$ showed significant relationship to all six input variables: sustainability intent and communication $(p<0.001)$, food waste diversion actions $(p<0.001)$, attitudes about composting $(p<0.001)$, composting $(p<0.001)$, reported household food waste $(p<0.001)$, and waste attitudes $(\phi<0.01)$ (Table 2; column 2 ). The model was highly significant as assessed by an ANOVA ( $\left.p<0.001, \mathrm{R}^{2}=0.368\right)$. Interestingly, respondents' reported personal household waste amounts were positively correlated with their intent to decrease waste; that is, the more food a student perceived they wasted, the higher their intent to decrease food waste. Fifty percent of respondents indicated that they only wasted $0 \%$ to $10 \%$ of their food.

It should be noted that asking students to report their household food waste percentages can be very challenging and represents a complex construct. A number of studies have shown that people consistently underestimate their own food waste. In fact, in multiple studies, between $45 \%$ and $70 \%$ of respondents indicate that they waste "very little," "hardly any," "no food," or " $0-10 \%$ of food" (Neff et al., 2015; Quested et al., 2013; Thyberg \& Tonjes, 2015). On the other hand, research suggests that participants reporting higher food 
Table 1. Summary of Likert Items and Factor Indexes

\begin{tabular}{|c|c|c|c|c|c|}
\hline Item (nested within factor) & $\begin{array}{l}\text { Item } \\
\text { loading }\end{array}$ & $\begin{array}{l}\text { Cronbach's } \\
\text { alpha }\end{array}$ & \% Agree & $\%$ Neutral & $\%$ Disagree \\
\hline Food waste diversion behaviors & & 0.648 & & & \\
\hline I eat leftovers & 0.476 & & 82.4 & 10.7 & 5.7 \\
\hline I check the refrigerator before shopping & 0.77 & & 77 & 13.3 & 8.7 \\
\hline I don't make lists or plan meals before shopping & 0.655 & & 18.2 & 19.6 & 61.2 \\
\hline I think about the portions of food that I take or cook & 0.44 & & 75.6 & 17.2 & 6.1 \\
\hline I prepare/cook some of my meals & $0.21 *$ & & 69.1 & 17.1 & 12.3 \\
\hline Intent to decrease food waste & & 0.752 & & & \\
\hline I think about the food waste I generate & 0.944 & & 70.7 & 20.2 & 8.3 \\
\hline I put effort into reducing food waste & 0.711 & & 70.1 & 21.2 & 7.9 \\
\hline I am interested in taking action to prevent food waste & 0.545 & & 64.8 & 28.1 & 6.7 \\
\hline Composting & & 0.813 & & & \\
\hline I know about the residence hall compost program & 0.747 & & 36.8 & 20.7 & 39.5 \\
\hline $\begin{array}{l}\text { When I compost, I feel like I'm contributing to the } \\
\text { greater good }\end{array}$ & 0.881 & & 81.8 & 13 & 1.9 \\
\hline Composting stinks and is gross & 0.881 & & 18.6 & 31.6 & 46.5 \\
\hline Sustainability intent and communication & & 0.621 & & & \\
\hline $\begin{array}{l}\text { I would be interested in attending a workshop on por- } \\
\text { tioning or cooking for one person }\end{array}$ & 0.709 & & 33.5 & 36 & 29.3 \\
\hline I talk to other people about food waste & 0.322 & & 23.2 & 31.1 & 41.8 \\
\hline I would enroll in a course with a sustainability theme & 0.523 & & 44.6 & 30.7 & 21.6 \\
\hline Waste attitudes & & 0.709 & & & \\
\hline $\begin{array}{l}\text { I understand food freshness labels (sell by, best by, use } \\
\text { by, expiration date, etc.) }\end{array}$ & 0.542 & & 71.1 & 18 & 7.3 \\
\hline $\begin{array}{l}\text { I believe that many materials can be reused or recycling } \\
\text { into something new }\end{array}$ & 0.731 & & 84 & 10.7 & 2.2 \\
\hline $\begin{array}{l}\text { I believe that proper waste disposal makes a positive } \\
\text { environmental impact }\end{array}$ & 0.736 & & 88.5 & 6.7 & 1.8 \\
\hline Attitudes about compost & & 0.638 & & & \\
\hline I compost my food scraps & 0.324 & & 35.8 & 22 & 39.4 \\
\hline $\begin{array}{l}\text { If I compost, I don't need to worry about source reduc- } \\
\text { tion (buying/preparing less food to avoid waste) }\end{array}$ & 0.592 & & 6.5 & 29.1 & 62 \\
\hline I dislike compost and composting & 0.666 & & 4.2 & 24.4 & 68.7 \\
\hline Food breaks down in the landfill, so it doesn't bother me & 0.946 & & 3.8 & 21.6 & 71.5 \\
\hline
\end{tabular}

* Item was removed from its original factor without significantly affecting its Cronbach's alpha and improving both the logical and correlational strength of factor "Food waste diversion actions."

waste percentages may actually be more informed and motivated to change their behaviors. Guilt has been shown to influence attitudes and intents toward food waste (Graham-Rowe et al., 2014). Our results are consistent: most respondents reported low amounts of food waste, but those reporting higher amounts of food waste also reported a higher intent to make change.

\section{Implications and Limitations}

Results of this research are promising. Students surveyed are thinking about food waste, interested 
Table 2. Linear Regression Models Indicating Relationships Between Measured Factors and Both "Intent To Decrease Food Waste" and "Reported Food Diversion Behaviors"

\begin{tabular}{lcc}
\hline & $\begin{array}{c}\text { Food waste diversion behav- } \\
\text { iors } \\
\text { Factor index/item }\end{array}$ & $\begin{array}{c}\text { model } \\
\text { Intent to decrease food waste } \\
\text { model }\end{array}$ \\
\hline -intercept & 0.889 & 0.288 \\
Food waste diversion actions index & $\begin{array}{c}\text { Dependent } \\
\text { Intent to decrease food waste index }\end{array}$ & $0.224 * * *$ \\
Composting index & $0.296 * * *$ & Dependent \\
Sustainability intent and communication index & $0.324 * * *$ & $-0.174 * * *$ \\
Waste attitudes index & & $0.312^{* * *}$ \\
Attitudes about compost index & $0.115^{* *}$ & $0.104 * *$ \\
Your household waste (\%) & & $0.184 * * *$ \\
$(n=495)$ & & $0.159 * * *$ \\
\hline
\end{tabular}

in taking action, and aware that they can make a difference. Respondents also demonstrate similar attitudes and perceived food waste-related behaviors as adults nationally (Neff et al., 2015). Food management skills, compost attitudes, sustainability attitudes, and reported household food waste are correlated with intent to reduce and with actual food-waste reduction behaviors. Therefore, these constructs are potential target areas for university food-waste diversion programming.

Although students have some knowledge around food waste and its drivers, many still underestimate their own food waste and that of consumers generally, indicating a potential knowledge gap that can be addressed by programming. Although knowledge does not always lead to action, the college period represents a time of significant change, identity progression, and habit development (Nelson et al., 2008). The fact that only $23 \%$ of students reported talking to others about food waste suggests an opportunity for opening up dialogue within university community spaces about improving local and global food systems.

Results also indicate a moderate level of composting (about 1 in 3 students) by participants. This suggests that the convenient availability of compost infrastructure (as is available in PSU residence halls) increases participation in composting programs. Implemented in 2011, Portland also has citywide composting for single-unit and some multi-unit dwellings. More composting participation should be encouraged through continued programming and infrastructure development.

This study also provides insights into factors that play a role in food waste diversion behavior of university students. The EFA and regression modeling show that our survey instrument was well suited for predicting the food waste diversion in this population. It would be beneficial to consider more items on barriers to food waste reduction and social influence, as both are central to the university setting. A confirmatory factor analysis on a survey instrument based on these results could strengthen the survey instrument for assessing intervention success. This model could be further applied to and assessed in other settings, such as event settings, households, and communities, in which programming could be implemented. Additionally, the use of random sampling over convenience sampling could improve future studies.

The strength of survey data is in understanding perceptions rather than actual behavior. Further research should compare self-perception from surveys to actual food waste behaviors measured through waste audits and observation, such as detailed daily journaling. Although linked food waste data is challenging to collect, some successful models exist, such as tagging or barcoding students' cafeteria trays individually during waste audits to identify their food waste in relation to survey responses 
(Whitehair et al., 2013). Furthermore, although the university setting provides opportunity for food-related behavior change (McComb et al., 2016; Nelson et al., 2008), common lingering questions include whether and how such change can be integrated into a student's long-term lifestyle. Since socialization, infrastructure for change, and campus culture play directly into student food-related behavior, positive attitudes may only lead to positive behaviors in such settings where those behaviors are most accessible and encouraged. Further research establishing the likelihood of positive food waste-related behavioral outcomes and how to ingrain those behaviors into long-term practice is necessary.

This study offers insight into the similarities of college-aged adults' food waste perceptions compared to data collected nationally (Neff et al., 2015). Our relatively large sample size and sampling at a university with a relatively diverse student body allow for some generalizations of results to other universities and colleges. On the other hand, the high proportion of residence hall students and freshman respondents in our sample should be acknowledged. Although limited by the restrictions of the residence halls, students in our study still cooked meals sometimes (69\%), engaged in meal prep and planning before shopping $(77 \%-81 \%)$, and portioned when cooking $(76 \%)$. Also, our city and university are actively focused on environmental sustainability and climate change. Therefore, some of the positive attitudes may be related to that context.

Individual behavior cannot be separated from its context. Today's food system contributes greatly to making waste a convenient, and even necessary, behavior. Therefore, we must also address the core issues that contribute to food waste at the community and policy levels. Our communities face many food-related challenges, including policies that encourage overproduction of commodity crops, food dumping in poor communities of that excess, junk food culture (also due in part to excess food), food apartheids (as opposed to the term food deserts; Penniman, 2018), confusing food freshness labels, standards that deem nutritious but oddly shaped food unsuitable for sale, inefficient or no compost- ing infrastructure, and externalized costs that build cheap food on a foundation of worker injustice, just to name a few. Although educational programming can support and facilitate some change, deep work must be done at the policy and community levels to promote a more just, nutritious, and efficient food system overall.

\section{Conclusion}

As food waste per household continues to increase worldwide (Thyberg \& Tonjes, 2015), food waste programming in educational settings is becoming an important tool to help address this trend (AlDomi et al., 2011; Buzby \& Guthrie, 2002; Merrow, Penzien, \& Dubats, 2012; Sarjahani, Serrano, \& Johnson, 2009; University of California, Davis Dining Services, 2015; Whitehair et al., 2013; Wilkie, Graunke, \& Cornejo, 2015). Improving food-waste related programming at universities provides a unique opportunity for change. Universities provide the structure (students eat many meals on campus) and community (campus culture can be influenced and influence students) for implementing food-related programming, and students are at a prime life stage for change. Research on food waste-related behavior within these settings specifically will ensure that programming is based on a context-specific understanding of the factors that underlie food waste-related behaviors. Addressing specific food waste behavioral factors in programming is important to improving and continuing this work and to developing university and community cultures that are aware and mindful of reducing food waste.

\section{Acknowledgments}

We would like to thank Dr. Thomas Kindermann for manuscript review. For survey instrument review, we thank Dr. Kerth O’Brien and Dr. Betty Izumi. For general guidance throughout the project, we thank Dr. Thomas Kindermann and Dr. Dilafruz Williams. For assistance with survey distribution we thank Anthony Hair and the Campus Sustainability Office team, Holly Carman-Fujioka with PSU Dining, Hannah Heller from the Center for Student Health and Counseling, and all the various student and staff volunteers. 


\section{References}

Al-Domi, H., Al-Rawajfeh, H., Aboyousif, F., Yaghi, S., Mashal, R., \& Fakhoury, J. (2011). Determining and addressing food plate waste in a group of students at the University of Jordan. Pakistan Journal of Nutrition, 10(9), 871-878. https://doi.org/10.3923/pjn.2011.609.617

Bajželj, B., Allwood, J. M., \& Cullen, J. M. (2013). Designing climate change mitigation plans that add up. Environmental Science \& Technology, 47(14), 8062-8069. https://doi.org/10.1021/es400399h

Barr, S. (2007). Factors influencing environmental attitudes and behaviors: A U.K. case study of household waste management. Environment and Behavior, 39(4), 435-473. https://doi.org/10.1177/0013916505283421

Bartholomew, D. J., Steele, F., Galbraith, J., \& Moustaki, I. (2008). Analysis of Multivariate Social Science Data, Second Edition. CRC Press.

Benítez, S. O., Lozano-Olvera, G., Morelos, R. A., \& Vega, C. A. de. (2008). Mathematical modeling to predict residential solid waste generation. Waste Management, 28(Supplement 1), S7-S13. https://doi.org/10.1016/j.wasman.2008.03.020

Betz, A., Buchli, J., Göbel, C., \& Müller, C. (2015). Food waste in the Swiss food service industry - Magnitude and potential for reduction. Waste Management, 35, 218-226. https://doi.org/10.1016/j.wasman.2014.09.015

Boslaugh, S. (2013). Statistics in a nutshell: A desktop quick reference (2nd ed.). Sebastopol, CA: O’Reilly Media.

Brook Lyndhurst. (2007). Food behaviour consumer research: Quantitative phase. Retrieved from the Waste and Resources Action Programme (WRAP) website: http://www.wrap.org.uk/sites/files/wrap/Food $\% 20$ behaviour $\% 20$ consumer $\% 20$ research $\% 20$ quantitative $\% 20$ jun \%202007.pdf

Browne, M. W. (2001). An overview of analytic rotation in exploratory factor analysis. Multivariate Behavioral Research, 36(1), 111-150. https://doi.org/10.1207/S15327906MBR3601 05

Buzby, J., \& Guthrie, J. (2002). Plate waste in school nutrition programs: Final report to Congress (No. EFAN-02-009). Retrieved from https://naldc.nal.usda.gov/download/48204/PDF

Buzby, J., Wells, H. F., \& Aulakh, J. (2014). Food loss_Questions about the amount and causes still remain. Retrieved from U.S. Department of Agriculture Economic Research Service website: https://www.ers.usda.gov/amberwaves/2014/june/food-loss-questions-about-the-amount-and-causes-still-remain/

Chrisafis, A. (2016, February 4). French law forbids food waste by supermarkets. The Guardian. Retrieved from https://www.theguardian.com/world/2016/feb/04/french-law-forbids-food-waste-by-supermarkets

Chrobog, K. (2015, November 12). South Korea: utting back on food waste. Pulitzer Center. Retrieved from http://pulitzercenter.org/reporting/south-korea-cutting-back-food-waste

Costello, A., \& Osborne, J. (2005). Best practices in exploratory factor analysis: Four recommendations for getting the most from your analysis. Practical Assessment, Research and Evaluation, 10(7), 1-9.

Campus Sustainability Office (CSO). (2010). Portland State University: Climate Action Plan. Portland, Oregon: Portland State University.

Doherty, M., Brannon, B., \& Crum, E. (2013). Portland State University solid waste assessment report. Portland, Oregon: Community Environmental Services.

Eccles, J. S., \& Wigfield, A. (2002). Motivational beliefs, values, and goals. Annual Review of Psychology, 53(1), 109-132. https://doi.org/10.1146/annurev.psych.53.100901.135153

Eilam, E., \& Trop, T. (2012). Environmental attitudes and environmental behavior-Which is the horse and which is the cart? Sustainability, 4(9), 2210-2246. https://doi.org/10.3390/su4092210

Evans, D. (2011). Blaming the consumer-once again: The social and material contexts of everyday food waste practices in some English households. Critical Public Health, 21(4), 429-440. https://doi.org/10.1080/09581596.2011.608797

Evans, D. (2012). Beyond the throwaway society: Ordinary domestic practice and a sociological approach to household food waste. Sociology, 46(1), 41-56. https://doi.org/10.1177/0038038511416150

Fabrigar, L. R., Wegener, D. T., MacCallum, R. C., \& Strahan, E. J. (1999). Evaluating the use of exploratory factor analysis in psychological research. Psychological Methods, 4(3), 272. https://doi.org/10.1037/1082-989X.4.3.272

Food and Agriculture Organization of the United Nations [FAO]. (2013). Food waste harms climate, water, land and biodiversity - new FAO report [Press release]. Retrieved from http://www.fao.org/news/story/en/item/196220/icode/ 
Feldstein, S. (2017). Wasting biodiversity: Why food waste needs to be a conservation priority. Biodiversity, 18(2-3), 7577. https://doi.org/10.1080/14888386.2017.1351891

Fiske, S. T., Gilbert, D. T., \& Lindzey, G. (2010). Handbook of social psychology, volume one. John Wiley \& Sons. https://doi.org/10.1002/9780470561119

Freedman, M. R., \& Brochado, C. (2010). Reducing portion size reduces food intake and plate waste. Obesity, 18(9), 1864-1866. https://doi.org/10.1038/oby.2009.480

Graham-Rowe, E., Jessop, D. C., \& Sparks, P. (2014). Identifying motivations and barriers to minimising household food waste. Resources, Conservation and Recycling, 84, 15-23. https://doi.org/10.1016/i.resconrec.2013.12.005

Gunders, D. (2012). Wasted: how America is losing up to 40 percent of its food from farm to fork to landfill (Report No. 12-06-B). Natural Resources Defense Council. Retrieved from https://www.nrdc.org/resources/wasted-how-america-losing-40-percent-its-food-farm-fork-landfill

Hair, A. (2013). Waste metrics. Retrieved August 11, 2015, from the Portland State University Campus Sustainability Office website: https://www.pdx.edu/sustainability/waste-metrics

Hebrok, M., \& Boks, C. (2017). Household food waste: Drivers and potential intervention points for design - An extensive review. Journal of Cleaner Production, 151, 380-392. https://doi.org/10.1016/i.jclepro.2017.03.069

Housing and Residence Life. (2019). Portland State University housing and residence life factbook. Portland State University.

Lehner, M., Mont, O., \& Heiskanen, E. (2015). Nudging - A promising tool for sustainable consumption behaviour? Journal of Cleaner Production. https://doi.org/10.1016/i.jclepro.2015.11.086

Leib, E., Ferro, J., Nielsen, A., Nosek, G., Qu, J., \& Gunders, D. (2013). The dating game: How confusing food date labels lead to food waste in America (NRDC No. 13-09-A). New York: Harvard Food Law and Policy Clinic and the Natural Resources Defense Council. Retrieved from https://www.nrdc.org/resources/dating-game-how-confusing-food-date-labels-lead-food-waste-america

Leib, E., Rice, C., Neff, R. A., Spiker, M. L., Schklair, A., \& Greenberg, S. (2016). Consumerperceptions of date labels: National survey. Harvard Food Law and Policy Clinic, National Consumers League, \& Johns Hopkins Center for a Livable Future. Retrieved from http://www.chlpi.org/wp-content/uploads/2013/12/Consumer-Perceptions-on-Date-Labels May-2016.pdf

Leigh Gibson, E. (2006). Emotional influences on food choice: Sensory, physiological and psychological pathways. Physiology \& Behavior, 89(1), 53-61. https://doi.org/10.1016/i.physbeh.2006.01.024

Lipinski, B., Hanson, C., Lomax, J., Kitinoja, L., Waite, R., \& Searchinger, T. (2013). Reducing food loss and waste (No. 2). Retrieved from United Nations Environment Programme (UNEP) website: https://pdf.wri.org/reducing food loss and waste.pdf

Lorenzo-Seva, U., \& Ferrando, P. J. (2015). POLYMAT-C: A comprehensive SPSS program for computing the polychoric correlation matrix. Behavior Research Methods, 47(3), 884-889. https://doi.org/10.3758/s13428-014-0511-x

McComb, S., Jones, C., Smith, A., Collins, W., \& Pope, B. (2016). Designing incentives to change behaviors: Examining college student intent toward healthy diets. Western Journal of Nursing Research, 38(9), 1094-1113. https://doi.org/10.1177/0193945916644705

McDermott, C., Elliott, D., Moreno, L., Broderson, R., \& Mulder, C. (2019). State of Oregon: food environmental impacts and actions-Wasted food measurement study. Oregon Department of Environmental Quality. Retrieved from https://www.oregon.gov/deq/mm/food/Pages/Wasted-Food-Study.aspx

McKenzie-Mohr, D., Nemiroff, L. S., Beers, L., \& Desmarais, S. (1995). Determinants of responsible environmental behavior. Journal of Social Issues, 51(4), 139-156. https://doi.org/10.1111/j.1540-4560.1995.tb01352.x

Merrow, K., Penzien, P., \& Dubats, T. (2012). Exploring food waste reduction in campus dining halls. Western Michigan University. Retrieved from https://wmich.edu/sites/default/files/attachments/ENVS $\% 204100 \% 20$ Final $\% 20$ Project $\% 20$ Report $\% 20-020$ Mer row, $\% 20$ Penzien, $\% 20$ Dubats.pdf

Moseley, A., \& Stoker, G. (2013). Nudging citizens? Prospects and pitfalls confronting a new heuristic. Resources, Conservation and Recycling, 79, 4-10. https://doi.org/10.1016/j.resconrec.2013.04.008

Neff, R. (2015). Introduction to the US food system: Public health, environment, and equity. San Francisco: Jossey-Bass. 
Neff, R. A., Spiker, M. L., \& Truant, P. L. (2015). Wasted food: U.S. consumers' reported awareness, attitudes, and behaviors. PLoS ONE, 10(6), e0127881. https://doi.org/10.1371/journal.pone.0127881

Nelson, M. C., Story, M., Larson, N. I., Neumark-Sztainer, D., \& Lytle, L. A. (2008). Emerging adulthood and collegeaged youth: An overlooked age for weight-related behavior change. Obesity, 16(10), 2205-2211. https://doi.org/10.1038/oby.2008.365

Nestle, D. M., Bittman, M., \& Baer, N. (2015). Soda politics: Taking on big soda (1st ed.). Oxford, UK: Oxford University Press.

Olhoff, A. (2018). UN Environment Emissions Gap Report 2018. United Nations Environment Programme (UNEP). Retrieved from https://www.unenvironment.org/resources/emissions-gap-report-2018

Oliveira, B., de Moura, A. P., \& Cunha, L. M. (2016). Reducing food waste in the food service sector as a way to promote public health and environmental sustainability. In W. Leal Filho, U. M. Azeiteiro, \& F. Alves (Eds.), Climate change and health: Improving resilience and reducing risks (pp. 117-132). Heidelberg: Springer Cham.

Oliver, J. (2010). Teach every child about food. Retrieved from http://www.ted.com/talks/jamie_oliver

Parfitt, J., Barthel, M., \& Macnaughton, S. (2010). Food waste within food supply chains: Quantification and potential for change to 2050. Philosophical Transactions of the Royal Society B: Biological Sciences, 365(1554), 3065-3081. https://doi.org/10.1098/rstb.2010.0126

Patel, R. (2012). Stuffed and starved: The hidden battle for the world food system - Revised and updated (2nd ed.). Brooklyn, N.Y.: Melville House.

Pelletier, L., Dion, S., Tuson, K., \& Green-Demers, I. (1999). Why do people fail to adopt environmental protective behaviors? Toward a taxonomy of environmental amotivation. Journal of Applied Social Psychology, 29(12), 2481-2505. https://doi.org/10.1111/j.1559-1816.1999.tb00122.x

Penniman, L. (2018). Farming while black: Soul Fire Farm's practical guide to liberation on the land. White River Junction, Vermont: Chelsea Green Publishing.

Pollan, M. (2008). In defense of food: an eater's manifesto (1st ed.). New York: Penguin Books.

Quested, T. E., Marsh, E., Stunell, D., \& Parry, A. D. (2013). Spaghetti soup: The complex world of food waste behaviours. Resources, Conservation and Recycling, 79, 43-51. https://doi.org/10.1016/j.resconrec.2013.04.011

Quested, T., Ingle, R., \& Parry, A. (2013). Household food and drink waste in the UK 2012 | WRAP UK (No. CFP102). Retrieved from WRAP website: http://www.wrap.org.uk/content/household-food-and-drink-waste-uk-2012

Rethink Food Waste through Economics and Data [ReFED]. (2016). A roadmap to reduce U.S. food waste by 20 percent. Rethink Food Waste: Through Economics and Data (ReFED). Retrieved from https://www.refed.com/downloads/ReFED Report 2016.pdf

Refsgaard, K., \& Magnussen, K. (2009). Household behaviour and attitudes with respect to recycling food waste Experiences from focus groups. Journal of Environmental Management, 90(2), 760-771. https://doi.org/10.1016/j.jenvman.2008.01.018

Sarjahani, A., Serrano, E. L., \& Johnson, R. (2009). Food and non-edible, compostable waste in a university dining facility. Journal of Hunger \& Environmental Nutrition, 4(1), 95-102. https://doi.org/10.1080/19320240802706874

Schafer, J. L., \& Graham, J. W. (2002). Missing data: Our view of the state of the art. Psychological Methods, 7(2), $147-177$. https://doi.org/10.1037/1082-989X.7.2.147

Siegrist, C. (2015). Organics diversion in college residence halls. BioCycle, 56(10), 29.

Thomas, C., \& Sharp, V. (2013). Understanding the normalisation of recycling behaviour and its implications for other pro-environmental behaviours: A review of social norms and recycling. Resources, Conservation and Recycling, 79, 11-20. https://doi.org/10.1016/j.resconrec.2013.04.010

Thyberg, K., \& Tonjes, D. (2015). Drivers of food waste and their implications for sustainable policy development. Resources Conservation and Recycling, 106, 110-123. https://doi.org/10.1016/j.resconrec.2015.11.016

University of California, Davis Dining Services. (2015). Waste reduction and elimination: UC Davis dining services. Retrieved October 1, 2015, from http://dining.ucdavis.edu/sus-recycling.html

University Communications. (2017). Portland State University | Profile. Retrieved August 2, 2017, from https://www.pdx.edu/profile/snapshot-portland-state 
Vidgen, H. A., \& Gallegos, D. (2014). Defining food literacy and its components. Appetite, 76, 50-59. https://doi.org/10.1016/j.appet.2014.01.010

Whitehair, K. J., Shanklin, C. W., \& Brannon, L. A. (2013). Written messages improve edible food waste behaviors in a university dining facility. Journal of the Academy of Nutrition and Dietetics, 113(1), 63-69. https://doi.org/10.1016/j.jand.2012.09.015

Wilkie, A., Graunke, R., \& Cornejo, C. (2015). Food waste auditing at three Florida schools. Sustainability, 7(2), 13701387. https://doi.org/10.3390/su7021370

Williams, B., Onsman, A., \& Brown, T. (2010). Exploratory factor analysis: A five-step guide for novices. Australasian Journal of Paramedicine, 8(3). Retrieved from https://ajp.paramedics.org/index.php/ajp/article/view/93

WRAP UK. (2017, February 24). Changes to food packaging and labels could save UK homes $\AA_{1}$ billion annually. Retrieved from http://www.wrap.org.uk/content/changes-food-packaging-and-labels-could-save-ukhomes- $\%$ C2 $\%$ A31-billion-annually

Yong, A. G., \& Pearce, S. (2013). A beginner's guide to factor analysis: Focusing on exploratory factor analysis. Tutorials in Quantitative Methods for Psychology, 9(2), 79-94. https://doi.org/10.20982/tqmp.09.2.p079 